\title{
PERFORACIÓN VESICULAR Y NEUMATOSIS PORTOMESENTÉRICA SECUNDARIAS A TRAUMA ABDOMINAL CONTUSO*
}

\author{
Drs. Sergio Pacheco S. ${ }^{1}$, Andrea Jiménez A. ${ }^{1}$, \\ José Miguel Martínez G. ${ }^{1}$, Mario Santamarina R. ${ }^{2}$ \\ 1 Unidad de Emergencia Adultos, Hospital Carlos Van Buren, Universidad de Valparaíso. \\ 2 Servicio de Radiología, Hospital Eduardo Pereira. Valparaíso. \\ Chile.
}

\section{Gallbladder rupture and portomesenteric pneumatosis secondary to a blunt abdominal trauma}

Paciente de sexo femenino de 73 años de edad consultó en unidad de emergencia por caída desde altura golpeándose el abdomen tres días atrás. Presentaba dolor abdominal difuso asociado a fiebre en las últimas $24 \mathrm{~h}$. Al ingreso se encontraba normotensa, taquicárdica, febril $\left(38^{\circ} \mathrm{C}\right)$. Al examen físico abdomen blando, depresible, con dolor difuso a la palpación profunda. Se realizó TC que mostró líquido libre en cavidad abdominal, extensa neumatosis portomesentérica, vesícula biliar colapsada (Figuras 1, 2, 3). Se realizó laparotomía exploradora evidenciando biliperitoneo difuso, perforación de 1 $\mathrm{cm}$ de diámetro en fondo vesicular, no presentaba colelitiasis. Durante la inducción anestésica la paciente presentó paro cardiorrespiratorio lo que requirió reanimación cardiopulmonar hasta revertir la situación, debido a esto se decidió realizar aseo de cavidad abdominal, colecistostomía y laparosto-

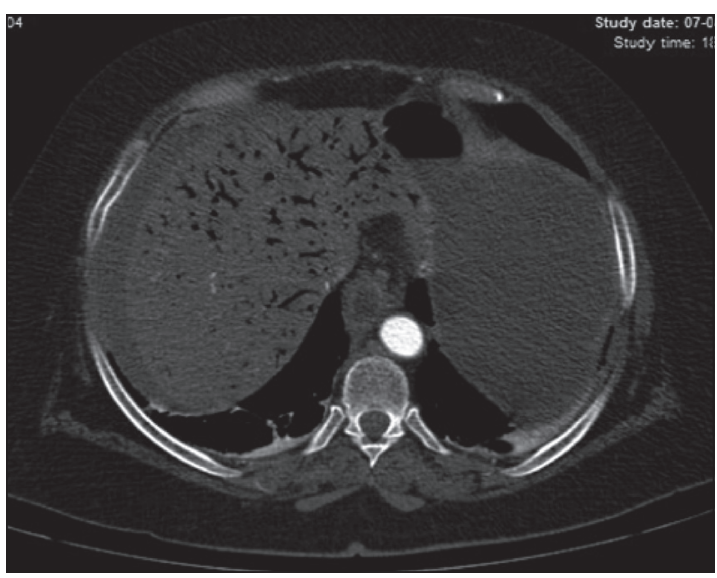

Figura 1. Corte transversal de TC de abdomen que muestra líquido perihepático y neumatosis en ramas portales intrahepáticas.

*Recibido el 2 de agosto de 2014 y aceptado para publicación el 29 de agosto de 2014.

Los autores declaran no tener ningún tipo de conflicto de intereses.

Correspondencia: Dr. Sergio Pacheco S.

sergiopacheco13@gmail.com 


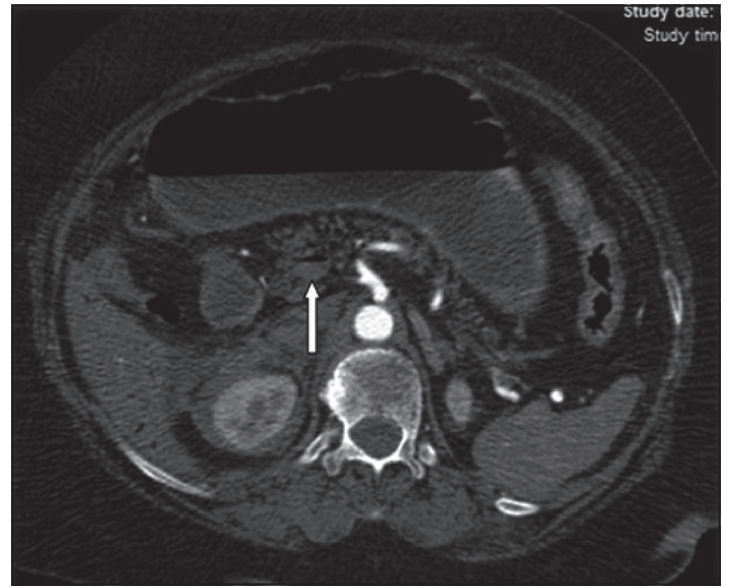

Figura 2. Corte transversal de TC de abdomen. La flecha muestra neumatosis en vena mesentérica superior.

mía contenida con VAC. Se trasladó a UCI, donde evolucionó estable con necesidad de drogas vasoactivas y ventilación mecánica. A las 48 h se realizó nuevo aseo peritoneal y cierre de pared abdominal, evolución posterior favorable siendo dada de alta al día quince. El diagnóstico de perforación vesicular por trauma abdominal contuso es poco frecuente y habitualmente tardío ${ }^{1,2}$. El tratamiento habitual es la colecistectomía, realizándose colecistostomía sólo en pacientes de extrema gravedad ${ }^{3}$.

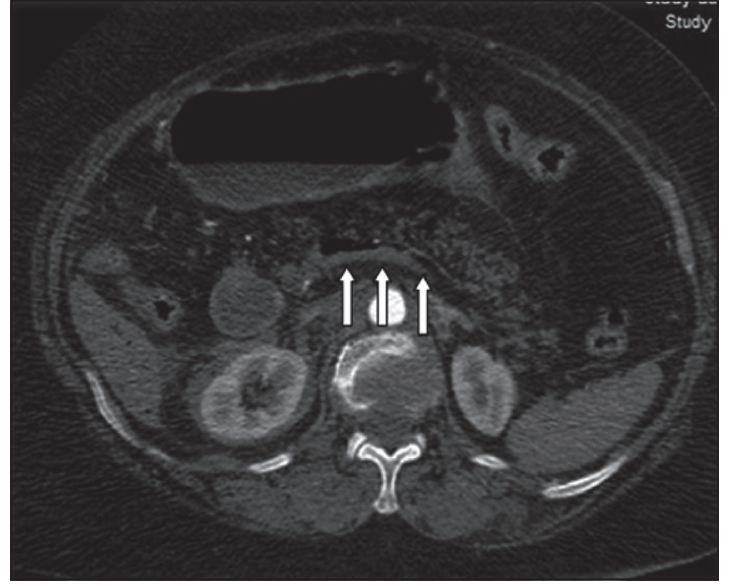

Figura 3. Corte transversal de TC de abdomen. Las flechas muestran neumatosis en tronco esplenomesaraico.

\section{Referencias}

1. Bainbridge J, Shaaban H, Kenefick N, Armstrong C. Delayed presentation of an isolated gallbladder rupture following a blunt abdominal trauma: a case report. J Med Case Reports 2007;1:52.

2. Birn J, Jung M, Dearing M. Isolated Gallbladder injury in a case of blunt abdominal trauma. J Radiol Case Rep. 2012;6:25-30.

3. Chastain BC, Seupaul RA. Traumatic gallbladder rupture. J Emerg Med. 2013;44:474-5. 